\title{
Los supuestos de aplicación extrajudicial de penas en el Derecho Canónico
}

\section{The Cases of Extrajudicial Application of Penalties in Canon Law}

\author{
Miquel Pons Portella \\ Abogado \\ Barcelona \\ miquel.pons@garrigues.com
}

Resumen: La aplicación extrajudicial de penas es una peculiaridad del Derecho Canónico que el vigente Código de 1983 claramente posterga frente al proceso criminal judicial. Sin embargo, durante las últimas décadas, este cauce procesal ha experimentado un notable resurgimiento a causa de la aprobación de una abundante normativa extracodicial que ha multiplicado los supuestos en que puede castigarse un delito canónico mediante decreto. Así, hoy por hoy existen regulaciones específicas sobre esta materia en hasta tres Congregaciones vaticanas, dado que en muchos asuntos el llamado procedimiento administrativo penal presenta grandes ventajas por su sencillez y su rapidez. Por todos estos motivos se hace preciso, en definitiva, un estudio de los supuestos en que se pueden castigar delitos canónicos por vía administrativa: ello nos permitirá tener una visión más completa de todo el ordenamiento jurídico de la Iglesia y, a su vez, nos dejará entrever qué aspectos del mismo podrían ser mejorados.

Palabras clave: Derecho penal canónico, Procedimiento administrativo penal, Decreto extrajudicial.
Abstract: The extrajudicial application of penalties is a distinctive feature of canon law that the current 1983 Code clearly places after the judicial criminal process. However, in recent years, this process has undergone a significant resurgence due to the approval of a plethora of extra-Code regulations that has increased the number of cases in which a canonical offense may be punished by decree. Thus, there are now specific regulations relating to this matter in up to three Vatican Congregations, because in many cases the so-called criminal administrative procedure offers significant advantages in terms of simplicity and efficiency. Given these reasons, in conclusion, a study of the cases in which canonical offenses can be punished by administrative means is needed, enabling a clearer vision of the legal system of the Church as a whole and, at the same time, as well as of what aspects might be improved.

Keywords: Canonical Criminal Law, Criminal Administrative Procedure, Extrajudicial Decree. 


\section{INTRODUCCIÓN}

L

a imposición o la declaración de una pena al responsable de un delito mediante decreto extrajudicial, posibilidad que se halla contemplada por el c. $1342 \$ 1$, es una peculiaridad singularísima del ordenamiento jurídico canónico, el cual -es importante recordarlo- tiene como misión esencial la búsqueda de la salvación de las almas (Salus animarum suprema $l e x)^{1}$. Sólo desde esta perspectiva se entiende que, ciertas circunstancias (motivos de discreción, celeridad y disponibilidad de medios, entre otros), aconsejen al Ordinario actuar de conformidad con lo dispuesto en el c. 1720. Al fin y al cabo, como ha recordado en fechas recientes el papa Francisco, el Concilio Vaticano II enseñó que el «Obispo en su Iglesia, de la que es constituido pastor y cabeza, es por eso mismo juez entre los fieles que se le han confiado» ${ }^{2}$.

Tan cierto es que el vigente Código de Derecho Canónico de 1983 prefiere el proceso judicial por ser «el que mayores garantías ofrece tanto desde la perspectiva de la sociedad eclesial como del sujeto que se somete al mismo» ${ }^{3}$, como que «la vía administrativa ha servido siempre para la conminación e imposición de penas en la Iglesia» y que, por añadidura, «esta vía ha sido de hecho preferida a la judicial, porque permite actuar con mayor rapidez y simplicidad atendiendo equitativamente a las necesidades espirituales y materiales del reo sin descuidar el interés general» ${ }^{4}$.

${ }^{1}$ Cfr. J. Herranz, Salus animarum, «principio dell'ordinamento canonico», Ius ecclesiae 12/2 (2000) 291-306; F. FILONI, La recepción del Código en los territorios de misión y las Facultades Especiales concedidas a la Congregación para la Evangelización de los Pueblos, Universidad San Dámaso, Madrid 2015, 23 pp., 17: «la Iglesia no es un ordenamiento jurídico cualquiera sino que es el "sacramento universal de salvación" [...]; por tanto, persigue la salus animarum como su ley suprema».

2 Carta Apostólica en forma de Motu Proprio Mitis Iudex Dominus Iesus, sobre la reforma del proceso canónico para las causas de declaración de nulidad matrimonial en el Código de Derecho Canónico (15 de agosto de 2015), apartado III: AAS 107 (2015) 959-960.

3 L. A. García Matamoro, El proceso judicial penal cc. 1721-1728 CIC 83, Revista Española de Derecho Canónico 70/175 (2013) 547-564. Véase especialmente la p. 550.

${ }^{4}$ E. LabandeIRa, Tratado de derecho administrativo canónico, Eunsa, Pamplona 1993, 536 pp., 286. Así, por ejemplo, en su «relación» durante la Plenaria de la Congregación para el Culto Divino y la Disciplina de los Sacramentos celebrada en septiembre de 2001, Mons. Francesco Pio Tamburrino, secretario del Dicasterio, al dar cuenta de los procedimientos relativos a la dispensa de las obligaciones sacerdotales y a la dimisión del estado clerical tramitados durante aquel quinquenio (1996-2001), explicó que aunque el proceso judicial «vale anche per i sacerdote non idonei che si rifiutano di chiedere la dispensa, per alcuni pochi casi (finora 22) per i quali fu dichiarata e dimostrata l'impossibilità di seuire la procedura giudiziaria, il Dicastero ne ha riferito al Santo Padre chiedendo ed ottenendo, di volta in volta, l'autorizzazione ad irrogare la dimissione dallo stato cleircale "in poenam ex 
Así las cosas, «durante la década de los años noventa, en pleno auge de los procesos contra los clérigos acusados de haber cometido abusos sexuales a menores, se planteó la cuestión de si canónicamente sólo cabía acudir al proceso judicial penal» para resolver tales asuntos, normalmente mediante la expulsión del estado clerical (c. $1336 \$ 1.5^{\circ}$ ). En estas dramáticas circunstancias se pusieron de manifiesto las dificultades que generaba tal cauce -los medios necesarios para su tramitación, la lentitud de su sustanciación, el llamado strepitus iudicii, las exigencias en materia probatoria...-, lo que dio lugar a la búsqueda de "otras vías" que permitiesen, sobre todo, una "rápida y decisiva acción" ${ }^{5}$. El campo estaba labrado, pues, para que empezasen a adoptarse un conjunto de "medidas de excepción", como las ha denominado la doctrina, que indudablemente «iba a contracorriente, respecto a los criterios establecidos por el Código para la aplicación de las sanciones penales, pero que respondía a un concreto deber de "suplencia", inherente también a la estructura jerárquica de la Iglesia» ${ }^{6}$. De esta forma, la escueta regulación codicial -apenas los cc. 1342 y 1720 - se ha visto acrecentada en los últimos años por una abundante normativa extra-codicial que da fe de la nueva vitalidad del procedimiento administrativo penal. Ha sido así como una vieja institución canónica -la aplicación extrajudicial de penas-, que no estuvo lejos de ser eliminada durante la elaboración del vigente Código ${ }^{7}$, está experimentando un nuevo auge.

Se comprende, en definitiva, que uno de los “criterios" que inspiraron la preparación, al comienzo de esta década, de un proyecto de reforma del Libro VI del Código de Derecho Canónico por parte del Pontificio Consejo para los Textos Legislativos fuese «permitir con carácter general que la autoridad llamada a castigar pudiese emplear la vía administrativa en lugar de la judicial». Este «criterio», sin embargo, «con la marcha de los trabajos, se ha ido mos-

officio"». Congregatio de Cultu Divino et Disciplina Sacramentorum, Notitiae 37 (2001) 401, 406, 428-433. Véase también I. Granado Hijelmo, Tratamiento penal del abuso de menores en el Derecho canónico general y particular de los Estados Unidos de América, Fidelium Iura 15 (2005) 135176, especialmente las pp. 167-168.

${ }^{5}$ F. R. AZNAR GIL, La expulsión del estado clerical por procedimiento administrativo, Revista Española de Derecho Canónico 67/168 (2010) 255-294. Véanse las pp. 266-267. Asimismo, D. Ciтo, La pérdida del estado clerical «ex officio» ante las actuales urgencias pastorales, Ius Canonicum 51 (2011) 69-101.

${ }^{6}$ J. I. ARRIETA, El proyecto de revisión del libro VI del Código de Derecho Canónico, Anuario de Derecho Canónico 2 (2013) 211-231. Véase especialmente la p. 213.

${ }^{7}$ Cfr. F. PÉREZ-MADRID, Derecho administrativo sancionador en el ordenamiento canónico: una propuesta para su construcción, Eunsa, Pamplona 1994, 206. 
trando cada vez más problemático», de tal modo que, «en el momento presente, son precisamente las cuestiones de procedimiento ligadas a la reforma del sistema penal las que hay que resolver» ${ }^{8}$.

Por todo ello, la labor que vamos a acometer es singularmente útil en las actuales circunstancias: analizar con detalle en qué situaciones concretamente es posible la aplicación extrajudicial de penas en el vigente ordenamiento canónico es básico para sopesar cuál puede ser la evolución del procedimiento administrativo penal y el papel que está llamado a jugar en el Derecho Canónico del siglo XXI. Para lograr nuestro objetivo final, en primer lugar expondremos la regulación vigente del susodicho procedimiento y luego pasaremos al objeto central de nuestro trabajo: estudiar los supuestos en que procede la aplicación de penas canónicas por decreto.

\section{Regulación VIgENTE}

1. En el Código de Derecho Canónico de 1983 tenemos que distinguir de las reglas generales -que son, como ya hemos dicho, los cc. 1342 y 1720 una serie de "casos especiales", que van desde las sanciones para salvaguardar la disciplina de los tribunales eclesiásticos (véase, entre otros, el c. 1457) hasta la expulsión del miembro de un instituto religioso (cc. 694-704) o la supresión de asociaciones (c. $326 \$ 1$ ). Sin embargo, en estos “casos" no vamos a entrar, dado que quedan extramuros del ámbito penal al formar parte, según la doctrina ${ }^{10}$, del «sistema canónico de derecho administrativo sancionador» ${ }^{11}$, por lo que realmente no constituyen supuestos de aplicación extrajudicial de penas.

${ }^{8}$ J. I. ARRIETA, El proyecto de revisión..., cit., 229-231.

9 E. LabANDEIRA, Tratado de derecho administrativo..., cit., 287.

${ }^{10}$ Cfr. F. PÉrez-MAdRID, Derecho administrativo..., cit., 182-196.

${ }^{11}$ J. Miras - J. CANOSA - E. Baura, Compendio de derecho administrativo canónico, Eunsa, Pamplona 2001, 116-117. En este punto no podemos hacer menos de lamentar, juntamente con estos autores, como «las distinciones entre ilícito penal e ilícito administrativo y derecho penal y derecho administrativo sancionador no están formalmente establecidas en derecho canónico», lo que muchas veces «obliga al sistema penal a extenderse más allá de lo que debería ser propio, ocasionando con ello la existencia de algunos tipos delictivos y algunas penas difícilmente encajables en un sistema penal riguroso». Somos partidarios de incluir en este difuso ordenamiento administrativo sancionador la reciente Carta Apostólica en forma de Motu Proprio Come una madre amorevole (4 de junio de 2016), que desarrolla el c. $193 \$ 1$ en el sentido de precisar las causas graves que permiten remover a un Obispo diocesano de su oficio y el procedimiento que debe seguirse para ello. Recuérdese que la remoción de un oficio, a diferencia de su privación (c. 196), no constituye pena canónica. 
2. Pero, como ya hemos apuntado, juntamente con esta regulación codicial también debemos tener muy en cuenta la extra-codicial que la Santa Sede ha adoptado "en los últimos años" fundamentalmente, aunque no sólo, para «afrontar determinadas actuaciones y conductas, delictivas y/o contra la disciplina, de clérigos que, por su gravedad, producen un gran escándalo entre los fieles y dañan seriamente a la Iglesia en su conjunto». El profesor José Bernal Pascual argumenta con toda razón que, «para garantizar su operatividad, tales normas van acompañadas de importantes derogaciones de la disciplina codicial en aspectos de cierto calado. En algunos casos, no resulta fácil defender la coherencia entre las nuevas disposiciones de la Santa Sede y lo establecido por el Código vigente» ${ }^{12}$. Porque, ciertamente, entre ambos grupos normativos existe la siempre compleja relación derecho ordinario derecho singular. En concreto, las regulaciones extra-codiciales que vamos a abordar seguidamente constituyen ejemplos de ius singulare por cuanto obedecen a «una ratio iuris specialis, esto es, a circunstancias peculiares surgidas en un concreto ámbito material, personal o espacial que aconsejan un tratamiento específico y adecuado». Las normas de derecho singular se hacen necesarias, en definitiva, cuando existen «circunstancias urgentes y extraordinarias a las que no subviene adecuadamente la normativa ordinaria». Por ello, «la característica del ius singulare es que la excepcionalidad de las circunstancias que lo legitiman limita también institucionalmente su producción, aplicación, interpretación y vigencia ${ }^{13}$. Debemos tener muy presentes estos criterios doctrinales al acometer el análisis de la siguiente normativa extra-codicial:

- Las facultades especiales de la Congregación para la Evangelización de los Pueblos concedidas por san Juan Pablo II el 3 de marzo de 1997 y confirmadas por Benedicto XVI el 30 de abril de $2005^{14}$, para la presentación al Santo Padre de los casos de expulsión in poenam del estado clerical, con la relativa dispensa de las obligaciones sacerdotales, incluido el celibato, para los clérigos culpables de graves violaciones del VI mandamiento (c. 1395) e incardinados en circunscripciones ecle-

12 J. Bernal Pascual, Nuevos desarrollos del procedimiento administrativo para la imposición de las penas, en J. LANDETE (ed.), La cooperación canónica de la verdad. Actas de las XXXII fornadas de Actualidad Canónica (11-13 de abril de 2012), Dykinson, Madrid 2014, 131-162. Véanse sobre todo las pp. 131-132.

13 I. GRanado Hijelmo, Tratamiento penal..., cit., 150-151.

${ }^{14}$ Cfr. J. Bernal Pascual, Nuevos desarrollos..., cit., 135. 
siásticas que carecen de estructuras judiciales adecuadas ${ }^{15}$. Es preciso enfatizar que estas facultades especiales constituyen normas de ius singulare fundadas, en este caso particular, en las circunstancias excepcionales que concurren en los «territorios de misiones», que son aquellos que -a la luz del art. 89 de la Constitución Apostólica Pastor bonus (28 de junio de 1988) ${ }^{16}$ - dependen de la Congregación para la Evangelización de los Pueblos.

1. Según la doctrina, «pueden considerarse como la primera normativa orgánica, aunque sea a través del instrumento jurídico de la facultad, sobre la dimisión [del estado clerical] ex officio desde la promulgación del Código de Derecho Canónico», que contempla esta pena en el c. $1336 \$ 1.5^{\circ}$. El «carácter orgánico» de tales facultades especiales se debe a que, primero, indican claramente a través de qué hechos delictivos producen sus efectos y cuáles son éstos; segundo, diseñan el ámbito subjetivo en que resultan de aplicación; tercero, determinan las estrictas y específicas condiciones que deben cumplirse para que sea procedente su puesta en funcionamiento; $y$, cuarto, regulan un procedimiento propio ${ }^{17}$. Sobre este último aspecto, baste señalar que, como ha advertido la doctrina, «aunque nos encontramos ante un procedimiento administrativo simplificado en comparación con un proceso judicial, no se trata tampoco de lo que se establece en el c. $1720 \gg^{18}$.

2. El papa Benedicto XVI, en fecha 19 de diciembre de $2008^{19}$, amplió las facultades especiales de la Congregación para la Evangelización de los Pueblos para incluir nuevos ilícitos penales en su ámbito y, asimismo, para permitir su aplicación a los miembros de las sociedades misioneras de vida apostólica de derecho pontificio que dependen de la propia Congregación y a los miembros de institutos de vida consagrada y de sociedades de vida apostólica, tanto de derecho pontificio como de derecho diocesano, que trabajan en territorios dependientes del mismo Dicasterio vaticano ${ }^{20}$.

15 Cfr. F. Filoni, La recepción del Código..., cit., 18 y 21-22.

${ }^{16}$ AAS 93 (1988) 841-912.

${ }^{17}$ Cfr. D. Cito, La pérdida ..., cit., 80-81.

${ }^{18}$ D. Ciтo, La pérdida..., cit., 82.

${ }^{19}$ Cfr. F. Filoni, La recepción del Código..., cit., 22; D. CiTo, La pérdida..., cit., 80.

20 Cfr. J. Bernal Pascual, Nuevos desarrollos..., cit., 135; F. Filoni, La recepción del Código..., cit., 22. 
- El art. 21 de la Carta Apostólica dada Motu Proprio Sacramentorum sanctitatis tutela sobre las normas acerca de los delitos más graves reservados a la Congregación para la Doctrina de la Fe, en la versión aprobada por Benedicto XVI en fecha 21 de mayo de $2010^{21}$.

1. La Sacramentorum sanctitatis tutela, promulgada originalmente por san Juan Pablo II el 30 de abril de 2001 22, fue dictada para "definir con mayor exactitud" lo dispuesto por el art. 52 de la Constitución Apostólica Pastor bonus, ya citada, según el cual la susodicha Congregación «examina los delitos cometidos contra la fe y también los delitos más graves cometidos contra la moral o en la celebración de los sacramentos, que le sean denunciados y, en caso necesario, procede a declarar o imponer sanciones canónicas a tenor del derecho, tanto común como propio». Todo ello -como leemos en su art. 1 $\$ 1-\ll$ sin perjuicio de la competencia de la Penitenciaría Apostólica y sin perjuicio de lo que se prescribe en la Agendi ratio in doctrinarum examine», a cuyos arts. 28 y 29 nos referiremos más adelante al tratar de los delitos contra la fe.

Nueve años después, la propia Congregación procedió a «una reforma del texto normativo citado, enmendándolo no íntegramente, sino solamente en algunas de sus partes, con el fin de mejorar su operatividad concreta». Ello dio lugar a la versión de la Carta Apostólica que se halla vigente desde 2010 y que tipifica como «delitos reservados» al Dicasterio las conductas ilícitas "más graves" contra la fe, la Eucaristía, la Penitencia y la moral, así como la atentada ordenación sagrada de una mujer ${ }^{23}$.

2. Al principio, la Sacramentorum sanctitatis tutela preveía en su art. 17 que los llamados delicta graviora «sólo se deben perseguir en proceso judicial». De este modo, la norma extra-codicial era incluso más rigurosa que el propio Código ${ }^{24}$ y ello pese a que la propia Con-

${ }^{21}$ AAS 102 (2010) 419-434. Véase una traducción española en la Revista Española de Derecho Canónico 68/170 (2011) 399-428.

22 AAS 93 (2001) 737-739. Véase una traducción española en la Revista Española de Derecho Canónico 61/157 (2004) 433-472.

23 Para su exposición detallada, véase F. R. AzNAR GIL, Los «graviora delicta» reservados a la Congregación para la Doctrina de la Fe. Texto modificado (2010), Revista Española de Derecho Canónico 68/170 (2011) 283-313, especialmente las pp. 290-302.

${ }^{24}$ Cfr. J. Bernal Pascual, Nuevos desarrollos..., cit., 137. 
gregación para la Doctrina de la Fe en el pasado ya había utilizado el procedimiento administrativo penal por "mandato especial" del Santo Padre ${ }^{25}$. Sin embargo, el 7 de febrero de 2003, san Juan Pablo II adoptó ex audientia la siguiente decisión ${ }^{26}$ :

«Se concede a la Congregación para la Doctrina de la Fe la facultad de dispensar el art. 17 en los casos claros y graves que, a juicio del Congreso Particular de la Congregación para la Doctrina de la Fe: a) pueden ser remitidos directamente al Santo Padre para la dimisión ex officio; o bien b) pueden ser tratados con el procedimiento abreviado que ofrece el c. 1720 por el Ordinario que, si es del parecer de proceder a la dimisión del reo, deberá solicitar a la Congregación para la Doctrina de la Fe la conminación de dicha pena por decreto» ${ }^{27}$.

El papa Benedicto XVI confirmó esta facultad el 6 de mayo de $2005^{28}$ y, un lustro después, la incluyó en el art. $21 \$ 2$ de la "versión revisada" ${ }^{29}$ de la Sacramentorum sanctitatis tutela, que a día de hoy contempla dos opciones procesales: primero, el procedimiento administrativo penal del c. 1720, que la Congregación puede incoar "de oficio" o puede autorizar al Ordinario para que lo tramite ${ }^{30}$; segundo, la presentación «directamente» ante el Santo Padre de los "casos gravísimos" para la dimisión del estado clerical o la deposición junto con la dispensa de la ley del celibato. En ambos casos, es importante subrayar que, mientras que en 2003 «estábamos ante

${ }^{25}$ Nos referimos al asunto de las ordenaciones presbiterales y episcopales ilegítimas conferidas por el arzobispo Pedro Martín Ngó-dinh-Thuc, que dio lugar a que la Congregación para la Doctrina de la Fe emitiese un Decreto (17 de septiembre de 1976) y una posterior Notificación (12 de marzo de 1983). En ambos documentos, que se hallan disponibles en el sitio web de la propia Congregación (<http://www.vatican.va/roman_curia/congregations/cfaith/index_sp.htm>, consultado el 7 de mayo de 2017), se alude explícitamente al referido «mandato especial».

${ }^{26}$ Cfr. I. Granado Hijelmo, Tratamiento penal..., cit., 167.

27 J. Bernal Pascual, Nuevos desarrollos..., cit., 138. En el supuesto del apartado a), según F. R. AzNAR GIL, Los «graviora delicta»..., cit., 308, «el Santo Padre adoptaba estas decisiones en audiencia concedida al Prefecto o al Secretario de la Congregación para la Doctrina de la Fe que, a su vez, daba el decreto de expulsión del estado clerical en nombre del Santo Padre y contra el que no cabía recurso, salvo la decisión del Santo Padre de modificar su decisión anterior. Además, el decreto de expulsión autorizaba al Ordinario a divulgar las razones de la expulsión si ello redundaba en interés de los niños y de los jóvenes».

${ }^{28}$ F. R. AZNAR GIL, Los «graviora delicta»..., cit., 308.

29 J. Bernal Pascual, Nuevos desarrollos..., cit., 140.

30 F. R. AZNAR GIL, Los «graviora delicta»..., cit., 307 y 309. 
unas facultades concedidas por el Romano Pontífice que se podían aplicar caso por caso después de estudiar seriamente el asunto», ahora «nos encontramos ante unas posibilidades más previstas por la ley, aunque bajo ciertas condiciones» ${ }^{31}$.

- Las facultades especiales de la Congregación para el Clero concedidas por Benedicto XVI el 30 de enero de 2009 para tramitar la expulsión del estado clerical de los clérigos que hubieran cometido algunos delitos mediante un proceso administrativo penal ${ }^{32}$.

1. Tras constatar «que pueden verificarse situaciones de grave indisciplina por parte del clero, en las cuales todo esfuerzo por resolver el problema con medios pastorales y canónicos, previstos ya en el Código de Derecho Canónico, no sean suficientes ni idóneos para reparar el escándalo, restablecer la justicia y hacer que el reo se enmiende», la Congregación para el Clero solicitó al papa emérito Benedicto XVI estas facultades especiales que efectivamente le fueron concedidas en fecha 30 de enero de 2009. El cardenal Cláudio Hummes, prefecto de la Congregación en cuestión, comunicó esta concesión mediante una Carta circular enviada el 18 de abril de $2009^{33}$, que estuvo seguida de otra misiva de fecha 17 de marzo de 2010 «para clarificar algunas cuestiones de la carta anterior» ${ }^{34}$.

2. Con estas facultades, en síntesis, «se permite la expulsión del estado clerical, utilizando el procedimiento administrativo penal, a los clérigos» que hayan «atentado matrimonio aunque sólo sea civilmente y que después de ser amonestados no hubieran cambiado de vida y continuaran en su vida irregular y escandalosa» o que sean «culpables de graves pecados externos contra el VI mandamiento»; que sean reos del delito previsto por el c. 1399 y que, a causa de su comportamiento improcedente, haya "necesidad y urgencia" de "evitar

31 J. Bernal Pascual, Nuevos desarrollos..., cit., 140-141.

32 Véase, para una traducción al español, la Revista Española de Derecho Canónico 67/168 (2010) 391-400 у 67/169 (2010) 923-930.

33 Cfr. F. R. AZnar GIL, La expulsión..., cit., 256. Asimismo, M. Golab, Facultades especiales para la dimisión del estado clerical (Congregación para el Clero de 30 de enero de 2009). Análisis y comentario, Ius Canonicum 50 (2010) 671-683. Véase singularmente la p. 671.

${ }^{34}$ F. R. AZnar GIL, Congregación para el clero. Carta a los Ordinarios sobre la aplicación de las facultades especiales concedidas a la Congregación para el clero por el Sumo Pontifice el 30 de enero de 2010 (17 de marzo de 2010). Comentario, Revista Española de Derecho Canónico 67/169 (2010) 931-933. Véase la p. 931. 
un objetivo escándalo"; o que hayan «abandonado el ministerio por un periodo superior a cinco (5) años consecutivos» siempre y cuando persistan «en tal ausencia voluntaria e ilícita del ministerio» ${ }^{35}$. En los dos primeros supuestos, la Congregación para el Clero interviene -en ciertos casos a ruego del Ordinario- antes de presentar la decisión tomada «al Romano Pontífice para su aprobación en forma específica», mientras que en el último la propia Congregación puede declarar directamente «la pérdida del estado clerical con la dispensa de las obligaciones sacerdotales, incluido el celibato» ${ }^{36}$.

\section{LOS REGÍMENES DE LA APLICACIÓN EXTRAJUDICIAL DE PENAS}

1. De conformidad con el c. $1717 \$ 1$, «siempre que el Ordinario ${ }^{37}$ tenga noticia, al menos verosímil, de un delito, debe investigar con cautela, personalmente o por medio de una persona idónea, sobre los hechos y sus circunstancias así como sobre la imputabilidad, a no ser que esta investigación parezca del todo superflua».

La "investigación previa" -así se intitula el capítulo I de la parte IV (el "proceso penal”) del libro VII ("los procesos") del Código- es una fase común no sólo a todas las modalidades del procedimiento administrativo penal, sino

${ }^{35}$ La doctrina discute acerca de si este supuesto de hecho reviste carácter delictivo: véase, para un resumen, J. BeRnal PASCUal, Nuevos desarrollos..., cit., 151.

${ }^{36}$ M. GOLAB, Facultades especiales..., cit., 673.

37 Sobre este concepto, véase A. CALABRESE, sub c. 1720, en Comentario exegético al Código de Derecho Canónico, Eunsa, Pamplona 1996, IV-2, 2075-2076. El apartado c) del número 68 del Directorio para el ministerio pastoral de los Obispos Apostolorum Successores (22 de febrero de 2004), al enumerar los «criterios del ejercicio de la función judicial», dispone que, «si tiene noticias de comportamientos que dañen gravemente el bien común eclesial, el Obispo debe investigar con discreción, sólo o por medio de un delegado, los hechos y la responsabilidad de sus autores. Cuando considere que ha recogido pruebas suficientes de los hechos que han dado origen al escándalo, proceda a reprender o amonestar formalmente al interesado. Pero donde esto no bastase para reparar el escándalo, restablecer la justicia y conseguir la enmienda de la persona, el Obispo dé inicio al respectivo procedimiento para la imposición de penas». Véase, en la doctrina, A. VIANA, El gobierno de la diócesis según el Derecho en el directorio «Apostolorum Successores», Ius Canonicum 46 (2006) 639-659. En concreto, sobre la publicación de este documento, véase la nota 1 en p. 639; y, sobre el epígrafe que nos ocupa, la p. 651: «otra manifestación de este principio de responsabilidad personal en el gobierno es el recurso al Derecho penal canónico cuando no existan otras soluciones menos duras para defender la comunión eclesial y el bien de las almas. En ocasiones son las circunstancias de la vida de la Iglesia y su reflejo en los medios de comunicación las que recuerdan que "existe" el Derecho penal canónico y que a veces puede resultar un doloroso deber su aplicación, sin dilaciones irresponsables». 
a cualquier proceso -sea judicial, sea administrativo- que se incoe para imponer una pena. Se trata de un "instituto jurídico autónomo" cuya "naturaleza" es "administrativa" ${ }^{38}$ y cuya responsabilidad recae, como es patente, sobre el Ordinario. La iniciación de esta investigación requiere de una «decisión del Ordinario, tomada mediante un acto jurídico formal (decreto), pudiendo éste proveer en el mismo acto al nombramiento del investigador ${ }^{39}$. Es condición positiva para iniciar la investigación el que de las noticias obtenidas se deduzcan indicios tales que lleven a considerar como probable la comisión de un delito». Sin embargo, esta fase puede omitirse por "superflua" cuando la notitia criminis carezca de verosimilitud, pero también cuando se trate de "delitos públicos y notorios". La finalidad de la investigación previa es «obtener la información necesaria sobre la verdad de los hechos cometidos y sobre su autor, es decir, determinar si la noticia sobre la comisión del delito tiene o no fundamento ${ }^{40}$, todo ello con pleno respeto a la buena fama tanto del investigado como de cualquier otro fiel que pudiera verse involucrado (c. $1717 \$ 2$ ). Por ello, el propio c. $1717 \$ 1$ exige que el Ordinario investigue cada asunto "con cautela", lo que aconseja prudencia sobre todo cuando aparecen casos que implican el fuero interno. También es importante que se recojan los "elementos de prueba" para poder poner en marcha, en su caso, el proceso penal, aunque no sea éste su «único y exclusivo objetivo o finalidad [...], sino más bien recoger todos aquellos elementos necesarios que permitan un ejercicio responsable de la función pastoral» ${ }^{41}$. Al concluir la investigación previa, en definitiva, el Ordinario debe hallarse en condiciones de tomar la trascendente decisión que contempla el c. $1718 \$ 1$.

2. Según esta disposición, «cuando se estime que ya se han reunido elementos suficientes», el Ordinario deberá dar por concluida la investigación

${ }^{38}$ Cfr. J. SANCHIS, sub Pars IV, en Comentario exegético..., cit., IV-2, 2057.

39 A éste, precisamente, se refiere el c. 1717 \$: «quien realiza la investigación tiene los mismos poderes e idénticas obligaciones que el auditor en un proceso; y, si se realiza después un proceso judicial, no puede desempeñar en él la función del juez». Véase M. CoRTÉs DiÉGUEZ, La investigación previa y el proceso administrativo penal, Revista Española de Derecho Canónico 70/175 (2013) 513-545, especialmente la p. 519.

40 Merece ser citado, como regla especial, el art. 3 de las «normas de procedimiento» para el ejercicio de la III facultad especial concedida a la Congregación para el Clero en 2009, anejas a la Carta del prefecto de 17 de marzo de 2010, que exige que la investigación previa sirva para concluir "con certeza moral" que «el abandono del clérigo es irreversible».

${ }^{41}$ J. SANCHIS, sub c. 1717, en Comentario exegético..., cit., IV-2, 2062-2064. 
previa y acometer la "valoración prudencial" de las tres "cuestiones" que enumera el c. $1718 \$ 1$ :

- El Ordinario tiene que determinar «si puede ponerse en marcha el proceso para infligir o declarar una pena». La "viabilidad" del procedimiento depende de tres requisitos de «carácter prevalentemente objetivo», a saber: graves indicios sobre la comisión del delito, graves indicios sobre la imputabilidad de su supuesto autor y posibilidad de que todo ello pueda ser probado en el fuero externo.

- El propio Ordinario también ha de valorar «si conviene hacerlo así, teniendo presente el c. 1341», el cual le exhorta a «promover el procedimiento judicial o administrativo para imponer o declarar penas, sólo cuando haya visto que la corrección fraterna, la reprensión u otros medios de la solicitud pastoral no bastan para reparar el escándalo, restablecer la justicia y conseguir la enmienda del reo». La "oportunidad" del proceso penal, así pues, depende de si los fines de la pena pueden conseguirse de otro modo, puesto que «entonces la pena no tiene ya razón de ser y, por consiguiente, el Ordinario, no sólo no está obligado a iniciar el proceso, sino que tiene la obligación de no iniciarlo». En efecto, «la Iglesia es sumamente remisa a la hora de acudir al instrumento penal para instaurar o restaurar la propia disciplina» ${ }^{42}$, porque -como disponía el c. $2214 \$ 2$ del Código de Derecho Canónico de 1917 a partir de un famoso texto del Concilio de Trento- «puede más, para con los que hay que corregir, la benevolencia que la austeridad, la exhortación más que las amenazas, y la caridad más que el poder» ${ }^{43}$.

- Finalmente, el Ordinario tiene que decidir «si debe utilizarse el proceso judicial o, cuando la ley no lo prohíbe, se ha de proceder por decreto extrajudicial». Como ha puesto de manifiesto la doctrina, esta elección final "no es completamente libre" ${ }^{44}$, más aún si tenemos en

${ }^{42}$ V. DE PAOLIS, sub c. 1342, en Comentario exegético..., IV-1, 389.

43 Ibid., sub c. 1342, en Comentario exegético..., IV-1, 398. Siguiendo a este autor, empero, el c. 1341 no puede interpretarse en términos de «indiferencia ante el delito o pasividad en la tarea de restablecer la justicia o de ayudar a los fieles para que retornen al camino de la conversión y de la salvación». Los «medios de la solicitud pastoral» que refiere el canon en cuestión «se contemplan como sustitución de la vía penal» y tienen que situarse «en la perspectiva de elección del camino que debe seguirse» en cada caso.

44 J. Miras - J. Canosa - E. Baura, Compendio de derecho..., cit., 126. 
cuenta que actualmente a la encrucijada del c. $1718 \S 1.3^{\circ}$ debemos sumar los varios sistemas extra-codiciales.

3. En efecto, los varios regímenes extra-codiciales que existen en la actualidad del procedimiento administrativo penal «sólo se aplicarán bajo determinadas condiciones, bastante exigentes». Así pues, el «Ordinario, una vez valorados los datos obtenidos en la investigación preliminar», tiene que «ponderar el camino a seguir en el tratamiento del caso concreto» ${ }^{45}$. En virtud del principio de especialidad (lex specialis derogat generali), si concurren los requisitos previstos en alguno de los susodichos regímenes extra-codiciales (ley especial), queda descartada la aplicación del Código (ley general). Por consiguiente, en primer lugar consideraremos en qué supuestos y bajo qué circunstancias procede la aplicación de aquéllos y sólo después, en segundo lugar, entraremos a considerar el sistema del vigente Código de Derecho Canónico.

\subsection{Regímenes extra-codiciales}

\subsubsection{Congregación para la Evangelización de los Pueblos}

1. La aplicación de las facultades especiales concedidas a la Congregación para la Evangelización de los Pueblos en 1997 y ampliadas en 2008 procede para la represión, mediante la pena expiatoria de expulsión del estado clerical (c. $1336 \$ 1.5^{\circ}$ ), de los ilícitos penales tipificados por el c. 1395, salvo el delito contra el VI mandamiento cometido por un clérigo con un menor, cuyo conocimiento se halla atribuido a la Congregación para la Doctrina de la $\mathrm{Fe}^{46}$. Mediante su ampliación de 2008, como decíamos, estas facultades especiales también pasaron a aplicarse, en su caso, a los reos del delito previsto en el c. $1394 \$ 1$-es decir: «a los clérigos que han atentado matrimonio y que, amonestados, no se arrepienten y continúan con su vida irregular y escandalosa»y «a los diáconos que han causado escándalo en el ámbito moral y han sido juzgados por el propio Obispo no idóneos para el presbiterado» ${ }^{47}$.

45 J. Bernal Pascual, Nuevos desarrollos..., cit., 132.

46 Cfr. J. Bernal Pascual, Nuevos desarrollos..., cit., 135.

47 Ibid., Nuevos desarrollos..., cit., 135. Este mismo autor añade también que «el Santo Padre concedió a la Congregación para la Evangelización de los Pueblos la facultad especial de intervenir según la norma del c. 1399, tratando directamente los casos o confirmando las decisiones de los Ordinarios competentes, siempre que éstos lo pidiesen, por la gravedad de la violación de la ley 
2. Desde la perspectiva subjetiva, tales facultades sólo pueden aplicarse a clérigos incardinados en aquellas circunscripciones eclesiásticas que dependen del aludido Dicasterio y que, además, «carecen de estructuras judiciales adecuadas», o sea: un promotor de justicia, un abogado y un tribunal de tres jueces $^{48}$. Sin embargo, tras las modificaciones de 2008, las facultades de 1997 también pasan a ser de aplicación, por un lado, a los miembros de las sociedades misioneras de vida apostólica de derecho pontificio que dependen de la propia Congregación; y, por otro, a los miembros de institutos de vida consagrada y de sociedades de vida apostólica, tanto de derecho pontificio como de derecho diocesano, que trabajan en territorios dependientes del Dicasterio, aunque -en este último caso- sólo cuando «los competentes superiores no actúan de modo eficaz, a juicio de la Congregación para la Evangelización de los Pueblos, para castigar la mala conducta de los propios miembros de modo que se acabe con la situación de escándalo» ${ }^{49}$.

3. A todo ello debemos añadir, por último, «una serie de condiciones de carácter claramente restrictivo ${ }^{50}$ que podemos sintetizar en los siguientes puntos:

- El hecho típico debe haber ocurrido en una circunscripción eclesiástica dependiente de la Congregación para la Evangelización de los Pueblos.

- El clérigo responsable tiene que haber sido castigado legítimamente con la pena medicinal de suspensión de toda potestad de orden y gobierno, de conformidad con el c. $1333 \$ 1$, por un congruo espacio de tiempo.

- Al propio clérigo tiene que habérsele impuesto, además, alguna de las penas expiatorias que enumera el c. $1336 \$ 1$.

- El clérigo responsable debe haberse negado obstinadamente a pedir la dispensa de sus obligaciones sacerdotales, incluido el celibato, con la subsiguiente pérdida de la condición jurídica clerical ${ }^{51}$.

\footnotetext{
y la necesidad y la urgencia de evitar un objetivo escándalo. Esta facultad lleva aneja [...] la aplicación de las penas perpetuas [...] a los diáconos por causas graves y a los presbíteros por causas gravísimas. Los casos se elevarán siempre al Papa para la aprobación en forma específica y decisión» (p. 137).

${ }^{48}$ Cfr. F. Filoni, La recepción del Código..., cit., 18 y 21.

49 J. Bernal Pascual, Nuevos desarrollos..., cit., 135; cfr. F. Filoni, La recepción del Código..., cit., 22.

50 Ibid., Nuevos desarrollos..., cit., 136.

${ }^{51}$ Cfr. D. Cito, La pérdida..., cit., 81-82.
} 


\subsubsection{Congregación para la Doctrina de la Fe}

1. Como queda explicado, el art. 52 de la Constitución Apostólica Pastor bonus autoriza a este Dicasterio para "examinar" solamente «los delitos cometidos contra la fe y también los delitos más graves cometidos contra la moral o en la celebración de los sacramentos». Este reducido ámbito de aplicación -de carácter exclusivamente objetivo- es concretado en la actualidad por los arts. 2 a 6 de la Sacramentorum sanctitatis tutela, que clasifica los llamados "delitos reservados" 52 a la Congregación para la Doctrina de la Fe en cinco grupos:

1. Delitos contra la fe: herejía, cisma y apostasía.

2. Delitos más graves contra la Eucaristía: profanación de las especies consagradas, atentado y simulación de la acción litúrgica del Sacrificio eucarístico, concelebración prohibida del mismo Sacrificio y consagración con finalidad sacrílega de una sola especie o de ambas.

3. Delitos más graves contra la Penitencia: absolución del cómplice en un pecado contra el VI mandamiento, atentada absolución sacramental o escucha prohibida de una confesión, simulación de la absolución sacramental, solicitación a cometer un pecado contra el VI mandamiento, violación directa e indirecta del sigilo sacramental, captación o divulgación mediática de una confesión sacramental.

4. Delito más grave de la atentada ordenación sagrada de una mujer.

5. Delitos más graves contra la moral: delito contra el VI mandamiento cometido por un clérigo con un menor de 18 años y adquisición, retención o divulgación por un clérigo de material pornográfico de menores de 14 años.

2. Por regla general, el art. 16 de la Sacramentorum sanctitatis tutela preceptúa que, cuando el Ordinario recibe «una noticia al menos verosímil de un delito más grave» de los que acabamos de ver, acomete autónomamente la investigación previa a no ser que se aplique el art. 17, que permite al Dicasterio realizar «los preliminares del proceso, que por derecho común competen al Ordinario o al Jerarca», cuando «el caso se lleva directamente a la Congregación sin haberse realizado la investigación previa». Sólo después, en su

\footnotetext{
52 Para su exposición detallada, como queda dicho, véase F. R. AZNAR GIL, Los «graviora delicta»..., cit., 290-302.
} 
caso $^{53}$, presenta el resultado obtenido a la Congregación para la Doctrina de la Fe, la cual -añade aún el mismo art. 16-, «si no avoca a sí misma la causa por circunstancias particulares, ordenará al Ordinario o al Jerarca proceder ulteriormente». Entonces, se aplicará el procedimiento del Código de Derecho Canónico, pero si el Dicasterio avoca el asunto, tendrá la doble opción prevista por el art. $21 \S 2$ :

- Tramitar un procedimiento administrativo penal de conformidad con el c. 1720, lo que la propia Congregación puede hacer "de oficio" o autorizando al Ordinario para que lo haga ${ }^{54}$. Como ha hecho notar la doctrina, el apartado $1^{\circ}$ del art. $21 \$ 2$ de la Sacramentorum sanctitatis tutela es una norma general, «es decir, no señala casuística, por lo que es aplicable a todos los delitos más graves y, en principio, a todas las penas». Ahora bien, que esta disposición empiece con las palabras "en ciertos casos" es indicativo, según los mismos autores, de que en el fondo se trata de «una excepción que sólo puede utilizarse después de examinar cada caso en cuestión y a la vista de las circunstancias del mismo (por ejemplo, evidencia de culpa, gran escándalo, peligro inminente para el culpable o las víctimas, etc.). Fuera de estos supuestos se seguirá la vía judicial» ${ }^{55}$.

- Presentar "directamente" los "casos gravísimos" ante el Santo Padre para la dimisión del estado clerical o la deposición junto con la dispensa de la ley del celibato. En tal circunstancia, el apartado $2^{\circ}$ del art. $21 \$ 2$ exige «que conste de modo manifiesto la comisión del delito», por lo que la doctrina considera aplicable este cauce procedimental a supuestos «en los que la culpabilidad del clérigo es clara y ha quedado bien documentada, como, por ejemplo, los casos en los que hay una condena civil» ${ }^{56}$.

3. En el supuesto particular de que la Congregación conozca de delitos contra la fe, también tenemos que tomar en consideración lo previsto por el

${ }^{53}$ Cfr. F. R. AZNAR GIL, Los «graviora delicta»..., cit., 307, nota 82: «lógicamente, aquí únicamente se contempla el supuesto de que la investigación previa haya dado como resultado que hay indicios de delito y que, por tanto, se debe proseguir con el proceso penal».

${ }^{54}$ Cfr. F. R. AZnAR GIL, Los «graviora delicta»..., cit., 307 y 309.

55 M. CoRTÉs DiÉGUEZ, La investigación previa..., cit., 531-532.

56 J. Bernal Pascual, Nuevos desarrollos..., cit., 139. 
Reglamento para el examen de las doctrinas de 29 de junio de $1997^{57}$, al que alude en su inciso final el art. $1 \$ 1$ de la Carta Apostólica dada Motu Proprio Sacramentorum sanctitatis tutela. El art. 2 de este Reglamento señala, para empezar, que los Pastores de la Iglesia «tienen el deber y el derecho de vigilar, ya sea individualmente, ya sea reunidos en Concilios particulares o en las Conferencias Episcopales, para que no se lesionen la fe y las costumbres de los fieles a ellos encomendados» ${ }^{58}$. Pero cuando interviene la Congregación para la Doctrina de la Fe, a través de alguno de los procedimientos que establece el Reglamento de 1997, y alcanza «la conclusión -en el seno de su Sesión Ordinaria- de que [el autor] ha incurrido en el delito de herejía, apostasía o cisma», de conformidad con el art. 28, «procede a declarar las penas latae sententiae incurridas». La doctrina ha afirmado que éste «no es ningún acto judicial, es un acto administrativo de carácter "declarativo" ${ }^{59}$. El mismo art. 28 -que fue aprobado en forma específica por el Santo Padre contrariis quibuslibet non obstantibus $^{60}$ - prevé, en su inciso final, que «contra tal declaración no se admite recurso», lo que se explica porque «el uso de los recursos podría traer consigo la dilación de la solución definitiva de estos procedimientos, con el consiguiente daño que las falsas doctrinas podían seguir haciendo a los fieles ${ }^{61}$. Por último, en caso de que la Sesión Ordinaria de este Dicasterio verificara «la existencia de errores doctrinales para los cuales no son previstas penas latae sententiae», el art. 29 dispone que «la Congregación procede a norma del derecho ya sea universal, ya sea propio». Se trata de «una capacidad sancionadora en relación con la existencia de errores doctrinales» que, pese a concebirse en un «sentido amplio e indeterminado», según la doctrina puede incidir sobre todo en las «sanciones penales» previstas respectivamente por los cc. 1364 y $1371^{62}$.

57 AAS 89 (1997) 830-835.

58 De hecho, el art. $2 \$ 2$ de la Sacramentorum sanctitatis tutela también recuerda que, «a tenor del derecho, compete al Ordinario o al Jerarca remitir, en caso necesario, la excomunión latae sententiae, y realizar el proceso judicial de primera instancia o actuar por decreto extrajudicial». Véase, al respecto, F. R. AZNAR GIL, Los «graviora delicta»..., cit., 291 y nota 17.

59 J. A. FuENTES, Nuevo Reglamento de la Congregación para la Doctrina de la Fe sobre el examen de las doctrinas, Ius Canonicum 38 (1998) 301-341. Véanse las pp. 335-336.

${ }^{60}$ Cfr. J. A. Fuentes, Nuevo Reglamento..., cit., 340: «esta norma, que se opone a una posibilidad que los cánones reconocen a los fieles, alcanza su pleno valor porque cuenta con la aprobación específica del Romano Pontífice».

${ }^{61}$ Ibid., Nuevo Reglamento..., cit., 340: «sólo se impiden los recursos para el caso que acabamos de señalar, es decir, en relación con los decretos en los que se declaran esas penas canónicas y por esos delitos. Por tanto, fuera de esas gravísimas sanciones, las demás resoluciones administrativas de la Congregación podrán ser recurridas».

${ }^{62}$ Ibid., Nuevo Reglamento..., cit., 336-337. 


\subsubsection{Congregación para el Clero}

1. Las facultades especiales otorgadas en 2009 a la Congregación para el Clero sirven para solventar tres supuestos muy concretos mediante la aplicación, a través de un procedimiento administrativo, de la pena de expulsión del estado clerical. Tales casos típicos son los siguientes ${ }^{63}$ :

- Los clérigos que hayan «atentado matrimonio aunque sólo sea civilmente y que después de ser amonestados no hubieran cambiado de vida y continuaran en su vida irregular y escandalosa» o que sean «culpables de graves pecados externos contra el VI mandamiento». Es decir: los clérigos que sean reos de los delitos tipificados por los cc. 1394 $\$ 1$ y 1395 .

- Los clérigos que hayan cometido una «infracción externa de una ley divina o canónica» y haya necesidad de castigarla, de conformidad con el c. 1399 , por su «especial gravedad», siempre que además urja «la necesidad de prevenir o de reparar escándalos».

- Los clérigos que hayan «abandonado el ministerio por un periodo superior a cinco (5) años consecutivos», siempre y cuando persistan «en tal ausencia voluntaria e ilícita del ministerio».

2. En cualquiera de los tres escenarios, para que el Dicasterio pueda aplicar debidamente las facultades especiales que estamos estudiando, y no remita a las normas generales del Código de Derecho Canónico, es preciso que concurran además estos requisitos ${ }^{64}$ :

- La imposibilidad objetiva o subjetiva, pero en cualquier caso bien comprobada, de que el clérigo responsable pueda pedir la dispensa de las obligaciones dimanantes del estado clerical.

- El fracaso de las medidas pastorales y canónicas adoptadas por el Ordinario para que el reo acabe con su contumacia, lo que también tendrá que acreditarse documentalmente.

- La existencia de graves dificultades, de naturaleza objetiva y en relación con el caso concreto, para la celebración de un proceso penal.

\footnotetext{
63 Cfr. F. R. AzNAR GIL, La expulsión..., cit., 256.

${ }^{64}$ Cfr. J. Bernal Pascual, Nuevos desarrollos..., cit., 144-145.
} 


\subsection{Régimen codicial}

Desestimada la posibilidad de acudir a cualesquiera de los regímenes extra-codiciales, para saber cuándo aplicar el c. 1720 -o sea: para saber cuándo, en virtud del Código de 1983, es posible imponer una pena extrajudicialmente- es preciso que analicemos el c. 1342, que regula la cuestión a partir de sendas exigencias positiva $(\$ 1)$ y negativa $(\$ 2)$.

\subsubsection{El requisito positivo: la cuestión de las "justas causas"}

De conformidad con el c. $1342 \$ 1$, «cuando justas causas dificultan hacer un proceso judicial, la pena puede imponerse o declararse por decreto extrajudicial; en cualquier caso, los remedios penales y las penitencias pueden aplicarse mediante decreto».

1. Esta disposición «es fruto de una larga y laboriosa tarea ${ }^{65}$ que refleja el enconado debate doctrinal entre aquellos «que querían que fuera obligatoria la incoación de un proceso penal en todos los casos» y aquellos otros que, por el contrario, «preferían un instrumento ágil y rápido como es precisamente la vía administrativa» ${ }^{66}$. Los autores son unánimes en el sentido de que el c. $1342 \$ 1$ privilegia la vía judicial ${ }^{67}$, aunque, durante la confección del Código, «dicha intención fue debilitándose más y más en las sucesivas elaboraciones hasta quedar casi imperceptible en la formulación misma»: en efecto, se pasó de exigir causae graves y probationes de delicto evidentes para aplicar la pena por decreto extrajudicial a pedir sólo iustae causae ${ }^{68}$. De hecho, el c. 1402 $\$ 2$ del CCEO establece que cuando «graves causas dificultan hacer un juicio penal y son ciertas las pruebas del delito, éste puede castigarse por decreto extrajudicial». Es patente, entonces, cómo las dos exigencias barajadas durante la elaboración del Código de Derecho Canónico de 1983 se incluyeron finalmente en el CCEO.

\footnotetext{
${ }^{65}$ V. DE PAOLIS, sub c. 1342, en Comentario exegético..., IV-1, 399.

${ }^{66}$ F. PÉreZ-MAdrid, Derecho administrativo..., cit., 207. Según V. DE PAolis, sub Titulus V, en Comentario exegético..., IV-1, 394, «evidentemente se trata de otro punto abierto que necesita todavía larga y atenta reflexión».

${ }^{67}$ Véase, por ejemplo, S. BuENo SALINAS, Tratado general de Derecho Canónico, Atelier, Barcelona 2004, 468, según el cual «el proceso judicial ha de ser siempre el modo ordinario de imponer o declarar penas».

${ }^{68}$ V. DE PAOLIS, sub c. 1342, en Comentario exegético..., IV-1, 399-400.
} 
2. Así las cosas, podemos interpretar la prótasis «cuando justas causas dificultan hacer un proceso judicial» en dos perspectivas. Desde un punto de vista amplio, la primera oración del c. $1342 \$ 1$ englobaría "infinidad de posibilidades": inexistencia de tribunal diocesano, incompatibilidad del delito cometido con la jurisdicción delegada del tribunal, orden jerárquico del reo con respecto de los jueces, carencia de medios o de personal, urgencia o necesidad de una mayor rapidez... Como es obvio, esta interpretación amplia de la fórmula "justas causas" del c. $1342 \$ 1$ incrementa la discrecionalidad del Ordinario, que es quien decide a la luz del c. $1718 \$ 1.3^{\circ}$, lo que por algún autor se relaciona con el carácter pastoral del ordenamiento penal canónico ${ }^{69}$. Por el contrario, si partimos de una perspectiva restrictiva, se requerirían unas causas «que impidan verdaderamente la celebración del proceso judicial» hasta el punto de alcanzar, según algún autor, «una auténtica imposibilidad moral de celebrar un juicio» ${ }^{70}$.

3. Sea como fuere, insistimos, para la sustanciación de un procedimiento administrativo penal es imprescindible la concurrencia del requisito positivo de las "justas causas" a que se refiere el c. $1342 \$ 1$, con una única excepción que establece el inciso final del mismo precepto: «en cualquier caso los remedios penales y las penitencias pueden aplicarse mediante decreto». Se refiere a las dos medidas punitivas de baja intensidad contempladas en el c. 1312 $\$ 3$ y cuya regulación específica se encuentra en los cc. 1339 y 1340, respectivamente $^{71}$.

\subsubsection{El requisito negativo: las exclusiones del c. 1342 \$ 2}

1. A la vez que debe haber "justas causas" que impidan la celebración de un juicio, como queda explicado, para que corresponda el procedimiento administrativo penal, el c. 1342 también exige que no se vayan a imponer ni a declarar «penas perpetuas, ni tampoco aquellas otras que la ley o precepto que las establece prohíba aplicar mediante decreto». Se trata de las llamadas

${ }^{69}$ Cfr. V. DE PaOlis, sub Titulus V, en Comentario exegético..., IV-1, 391-393.

${ }^{70}$ F. PÉREZ-MADRID, Derecho administrativo..., cit., 218-219.

${ }^{71}$ Cfr. F. R. Aznar GiL, Las sanciones en la Iglesia, en M. Cortés Diéguez - J. SAN José (coordinadores), Derecho Canónico, vol. II: El Derecho en la Misión de la Iglesia, BAC, Madrid 2006, 223254. Véanse sobre todo las pp. 238-239. 
«prohibiciones para el empleo de la vía administrativa $»^{72}$ : verdaderos requisitos negativos que, en caso de existir, imposibilitan la opción procedimental de aplicar una pena canónica por decreto extrajudicial.

2. La primera exclusión son las "penas perpetuas" que, en virtud del c. $1342 \$ 2$, «no se pueden imponer o declarar por decreto». A la luz del c. 1312 $\$ 1$, sólo quedan excluidas algunas "penas expiatorias" (c. $1336 \$ 1$ ), que por regla general «pueden ser perpetuas y temporales, bien por un tiempo determinado o bien por un tiempo indeterminado» ${ }^{73}$, dado que las "penas medicinales o censuras" -a saber: excomunión, entredicho y suspensión ${ }^{74}$ - no pueden ser perpetuas "por su misma naturaleza" ". Esta exclusión incluye todas las que tengan tal consideración, «tanto si se trata de penas perpetuas por naturaleza, como si son penas irrogadas de hecho con carácter de perpetuidad». Entre las primeras destaca la «expulsión del estado clerical» (c. $1336 \$ 1.5^{\circ}$ ), «que es perpetua por naturaleza, aunque se haya previsto la posibilidad de readmisión por indulto de la Santa Sede» ${ }^{76}$. En realidad, el c. $1425 \$ 1.2^{\circ}$ reserva a «un tribunal colegial de tres jueces» aquellas "causas penales" que versen «sobre delitos que pueden castigarse con la expulsión del estado clerical» [apartado a)] o que traten de «infligir o declarar una excomunión» [apartado b)], por lo que en ambos supuestos queda excluido absolutamente el procedimiento administrativo penal $^{77}$.

3. Este c. $1425 \$ 1.2^{\circ}$, que acabamos de glosar, es un buen ejemplo práctico de la segunda exclusión que establece el c. $1342 \$ 2$ al disponer que tampoco pueden imponerse ni declararse extrajudicialmente «aquellas otras [penas] que la ley o precepto que las establece prohíba aplicar mediante decreto». El fundamento de este canon son los principios de prudencia - «el legislador no quiere cerrar la posibilidad de resolver obligatoriamente determinadas si-

72 F. PÉREZ-MADrID, Derecho administrativo..., cit., 218. Una previsión semejante, pero mucho más concreta, la hallamos en el inciso final del c. 1402 \$ 2 del CCEO, según el cual no pueden castigarse por decreto extrajudicial "la privación del oficio, del título, de las insignias", "la suspensión de más de un año", "la reducción al grado inferior", "la deposición" ni "la excomunión mayor".

73 F. R. AZNAR GIL, Las sanciones..., cit., 236-238.

${ }^{74}$ Ibid., Las sanciones..., cit., 232.

75 F. PÉREZ-MADRID, Derecho administrativo..., cit., 218.

${ }^{76}$ V. DE PAOLIS, sub c. 1342, en Comentario exegético..., IV-1, 399-400.

77 Cfr. E. LaBANDEIRA, Tratado de derecho admimistrativo..., cit., 285. 
tuaciones por medio de un proceso penal judicial»- y subsidiariedad $-\ll$ las situaciones dentro de la Iglesia, tan varias y diversificadas, hacen natural que en esta materia existe una sensibilidad distinta»-. Por ello, con el c. $1342 \$ 2$, «el legislador universal autoriza al legislador particular a convertir en obligatorio, en el ámbito de su propia competencia, el proceso judicial para la imposición de penas», aunque «tan sólo en el momento constitutivo de la ley o del precepto penal» ${ }^{78}$. Así pues, como ha hecho notar la doctrina, el Código de 1983 «ha querido que sea susceptible de prohibición sólo la vía administrativa y sin embargo, nada dice respecto al proceso [judicial]» ${ }^{79}$, por lo que queda confirmado lo que apuntábamos antes: «el proceso penal constituye todavía la vía privilegiada por el legislador canónico» ${ }^{80}$.

\section{LA DECISIÓN SOBRE EL RÉGIMEN APLICABLE}

1. Como se desprende claramente de los $\$ \$ 2$ y 3 del c. 1718, el Ordinario es quien toma la decisión sobre cuál de los regímenes del procedimiento administrativo penal debe seguirse. Es quien decide, en definitiva, si nos encontramos o no ante uno de los supuestos en que procede la aplicación extrajudicial de penas. Esta trascendente decisión es adoptada mediante un decreto que -como dispone el c. 48- es «el acto administrativo de la autoridad ejecutiva competente, por el cual, según las normas del derecho y para un caso particular, se toma una decisión o se hace una provisión que, por su naturaleza, no presuponen la petición de un interesado».

Así pues, esta resolución interlocutoria queda sujeta a la disciplina general de los decretos singulares ${ }^{81}$ al menos en los siguientes aspectos:

- En virtud del c. 50, que «regula un procedimiento mínimo que debe seguir la autoridad antes de tomar la decisión de dar un concreto decreto singular», el Ordinario tiene la obligación de recabar "las informaciones y pruebas necesarias" y, "en la medida de lo posible", oír a "aquellos cuyos derechos puedan resultar lesionados".

${ }^{78}$ V. DE PAOLIS, sub c. 1342, en Comentario exegético..., IV-1, 400-401.

79 F. PÉREZ-MADRID, Derecho administrativo..., cit., 218.

${ }^{80}$ V. DE PaOLIS, sub c. 1342, en Comentario exegético..., IV-1, 401.

81 Cfr. M. Cortés Diéguez, Las fuentes del derecho canónico, en M. Cortés DiÉGueZ - J. SAN José (coordinadores), Derecho Canónico, vol. I: El Derecho del Pueblo de Dios, BAC, Madrid 2006, 77 153. A continuación seguiremos las pp. 127-129. 
En este sentido, el c. $1718 \$ 3$ previene que, al dar el decreto que ahora nos ocupa, «conviene que el Ordinario, según su prudencia, oiga a dos jueces o a otros jurisperitos». Nada dispone, en cambio, sobre «aquellos cuyos derechos puedan resultar lesionados», a diferencia de lo que ocurre con el c. $1469 \$ 3$ del CCEO, que obliga al Jerarca a oír "sobre el delito", "antes de decidir" si debe actuar por juicio penal o por decreto extrajudicial, «al acusado y al promotor de justicia». Sin embargo, algún autor ha entendido que tal omisión ha sido intencionadamente dispuesta por el legislador «para evitar posibles prejuicios». Por ello, y aunque no se prohíbe en absoluto la intervención del investigado, «se aconseja recurrir a la opinión de expertos que no hayan intervenido en la investigación, o que no deban intervenir posteriormente en el proceso en el caso de que se decida ponerlo en marcha» ${ }^{82}$.

- Según el c. 51, «el decreto ha de darse por escrito, y si se trata de una decisión, haciendo constar los motivos, al menos sumariamente».

El requisito de la escritura es general para todos los actos administrativos, según el c. 37, y, pese a que no es necesario para la validez, es básico para la eficacia del decreto a través de su notificación, como veremos enseguida. Asimismo, la motivación -aunque sea sumaria- resulta imprescindible para la posterior interposición de recursos por el perjudicado, si procede.

- Los efectos de cualquier decreto singular, de conformidad con el inciso final del c. $54 \$ 1$, se producen «a partir del momento en que es intimado al destinatario por orden de quien lo decretó».

Por ello, entendemos que el decreto del c. 1718 también deberá ser notificado al reo para que pueda ponerse "en marcha", como leemos en su $\$ 1.1^{\circ}$, el proceso penal a través de la vía por la que haya optado el Ordinario. El régimen jurídico de esta notificación aparece regulado en los cc. 55 y 56 .

82 J. SANCHIS, sub c. 1718, en Comentario exegético..., cit., IV-2, 2071. Mientras que los jueces a que se refiere el c. $1718 \$ 3$ tienen que ser eclesiásticos, el término «jurisperitos» (iuris periti) «deja abierta la puerta a cualquier experto en Derecho -no necesariamente en Derecho canónicocuyo parecer pueda ser útil al Ordinario». Véase también F. PÉrEZ-MADrID, Derecho administrativo..., cit., 217. 
2. Dispone asimismo el c. $1718 \$ 2$ que «el Ordinario ha de revocar o modificar el decreto a que se refiere el $\$ 1$, siempre que, por surgir elementos nuevos, le parezca que debe decidir otra cosa». Para ello, según el ya comentado c. $1718 \$ 3$, también es conveniente que «según su prudencia, oiga a dos jueces o a otros jurisperitos».

El presupuesto para la aplicación del c. $1718 \$ 2$ es la aparición de "elementos nuevos" que pueden ser desde la enmienda del reo hasta el descubrimiento de pruebas, para citar sólo dos ejemplos. Ello podrá dar lugar a la revocación del decreto - es decir: una nueva decisión de la autoridad competente por la que, en palabras del c. $58 \$ 1$, “deja de tener fuerza” la anterior- o, alternativamente, a su modificación -que «consiste en la corrección del decreto, conservando éste sus elementos válidos»-. En ambos supuestos, la activación del c. $1718 \$ 2$ puede «hacerse por iniciativa del Ordinario o también a instancia de parte interesada ${ }^{83}$. Es claro, así pues, que contra el decreto del c. 1718 cabe abrir la vía del recurso administrativo, primero ante el propio Ordinario (c. $1734 \$ 1$ ) y luego ante el Superior jerárquico (c. $1737 \$ 1)^{84}$.

La estimación de este recurso administrativo -0 , incluso, su revisión de oficio por el propio Ordinario- puede dar lugar a una sustitución procedimental: de la vía judicial a la vía administrativa o de la vía administrativa a la vía judicial. Considera, en efecto, la doctrina, aunque no de modo unánime, que «no hay datos suficientes en el Código que impidan ese paso, cuando en algún supuesto, por datos que se obtengan posteriormente en el procedimiento, se vea que no concurren justas causas para seguir el procedimiento extrajudicial» ${ }^{85}$. Así, mientras que la remisión de la vía administrativa a la vía judicial «en cualquier momento del procedimiento» no debería generar, en principio, demasiados inconvenientes, más compleja se presenta la posibilidad inversa: un proceso judicial sólo podría mutar en procedimiento administrativo mediante una «renuncia en la instancia», resolución que -de conformidad con el c. 1724- debe tomar el promotor de justicia «por mandato o con el consentimiento del Ordinario que tomó la decisión de iniciar el proceso» y que precisa de la aceptación del acusado no ausente ${ }^{86}$.

83 J. SANCHIS, sub c. 1718, en Comentario exegético..., cit., IV-2, 2070-2071.

${ }^{84}$ Cfr. F. R. AZnar GIL, La expulsión..., cit., 263.

${ }^{85}$ F. PÉREZ-MADRID, Derecho administrativo..., cit., 217.

${ }^{86}$ J. SANCHIS, sub c. 1718, en Comentario exegético..., cit., IV-2, 2071. 


\section{ConClusión}

El Código de Derecho Canónico de 1983 optó claramente por el proceso judicial como el cauce más idóneo para la imposición de penas. Y ello a pesar de que, como escribiera el profesor Eduardo Labandeira hace varias décadas, tras el Código de 1917, "en la práctica" se abandonó la vía judicial para preferir "únicamente" la administrativa «por diversas razones: su rapidez, facilidad y menor publicidad, y porque no requiere una especial formación jurídica en quien la emplea; también es la más adecuada para las penas menos graves y los delitos de más fácil comprobación ${ }^{87}$. Esto no obstante, insistimos, el Código de 1983 optó por admitir sólo el procedimiento administrativo cuando concurran "justas causas" para ello, lo que no constituye una cláusula abierta a una máxima discrecionalidad, sino una expresa llamada de atención a la aplicación prudente de una decisión reflexiva y motivada en casos concretos.

Durante los últimos tiempos, sin embargo, se ha puesto de manifiesto que el procedimiento administrativo penal plantea unas potencialidades que pueden convertirlo en la solución de muchos problemas actuales. La multiplicación de los supuestos de ius singulare en que resulta procedente la aplicación extrajudicial de penas es un síntoma evidente del renovado auge que experimenta en la actualidad este cauce procedimental. De algún modo, la realidad de las cosas ha acabado imponiéndose y ha hecho patente, por añadidura, «la necesidad de compensar un "exceso" de medidas de garantía [judicial], de origen civil, que habían contribuido a paralizar y volver ineficaz el sistema penal canónico, entre otras cosas porque [...] este último ya posee naturalmente otros mecanismos, que en la sociedad civil no existen, para equilibrar las sanciones y moderar cualquier tipo de excesos» ${ }^{88}$. Siempre que, como es natural, haya operadores jurídicos capacitados para tramitarlo y se respete con rigor la normativa que lo regula.

En este último sentido, sería altamente deseable una reforma legal que dote de una mayor coherencia a la pléyade de normas extra-codiciales de la que hemos dado cumplida cuenta en estas páginas y cuya prolijidad es inversamente proporcional a la parquedad del Código de Derecho Canónico de 1983 sobre este crucial asunto. Es verdad, como hemos visto, que estas regu-

87 E. LABANDEIRA, Tratado de derecho administrativo..., cit., 283.

88 J. I. ARRIETA, El proyecto de revisión..., cit., 230. 
laciones extra-codiciales del procedimiento administrativo penal están específicamente diseñadas para tres concretos Dicasterios de la Curia Romana -Evangelización de los Pueblos, Doctrina de la Fe y Clero- y que se hallan plenamente justificadas en la atención debida a situaciones excepcionales: territorios de misión, delitos más graves, pena de expulsión del estado clerical... Pero, al mismo tiempo, la dispersión y la falta de sistematicidad de estas normas de derecho singular complican la tarea de los operadores del Derecho Canónico -sobre todo, la misión del Ordinario en el trance de optar por una vía $\mathrm{u}$ otra de conformidad con el c. $1718 \$ 1.3^{\circ}-\mathrm{y}$ añaden incertidumbre e inseguridad en un ámbito extremadamente sensible. Como ha argumentado Francis G. Morrisey, ante esta evidente falta de claridad, «un procedimiento que inicialmente ha sido establecido para acabar con los casos de abusos sexuales a niños puede también extenderse para ser aplicado a otras instancias. Por ejemplo, un sacerdote que se opone a su obispo (y quizá adecuadamente) puede un día tener presentado su caso para ser desprovisto del estado clerical...» ${ }^{89}$.

La existencia de normativa extra-codicial, cuya necesidad parece indudable, no puede menoscabar la consideración del Código de 1983 como «Corpus principal de leyes eclesiásticas para la Iglesia latina» porque de este modo podría llegarse a frustrar su función de «crear en la sociedad eclesial un orden tal que, asignando la parte principal al amor, a la gracia y a los carismas, haga a la vez más fácil el crecimiento ordenado de los mismos en la vida tanto de la sociedad eclesial como también de cada una de las personas que pertenecen a ella» ${ }^{90}$. En efecto, las normas extra-codiciales tendrían que respetar siempre los grandes principios del Código -por ejemplo, la promulgación mediante publicación que establece el c. $8 \$ 1$ - a fin de asegurar la coherencia de todo el ordenamiento jurídico canónico y evitar, al mismo tiempo, los riesgos jurídicos de inseguridad e incertidumbre que antes denunciábamos.

Sin lugar a dudas, la antigua institución del Derecho Canónico que hemos estudiado en estas páginas se halla ante el reto de una reforma que debe servir en primer término para aclarar dudas y resolver interrogantes en cuanto a los supuestos en que puede aplicarse, pero también para consolidar definitivamente la aplicación extrajudicial de penas como un instrumento más del ordenamiento jurídico de la Iglesia.

${ }^{89}$ Citado por F. R. AzNAR GIL, La expulsión..., cit., 272.

${ }^{90}$ San Juan Pablo II, Constitución Apostólica Sacrae disciplinae leges para la promulgación del nuevo Código de Derecho Canónico (25 de enero de 1983): AAS 75 (1983), Pars II, XI y XIII. 


\section{Bibliografía}

ARrieta, J. I., El proyecto de revisión del libro VI del Código de Derecho Canónico, Anuario de Derecho Canónico 2 (2013) 211-231.

AZnar GIL, F. R., Las sanciones en la Iglesia, en M. Cortés DiéGueZ - J. SAN José (coordinadores), Derecho Canónico, vol. II: El Derecho en la Misión de la Iglesia, BAC, Madrid 2006, 223-254.

—, La expulsión del estado clerical por procedimiento administrativo, Revista Española de Derecho Canónico 67/168 (2010) 255-294.

-, Congregación para el clero. Carta a los Ordinarios sobre la aplicación de las facultades especiales concedidas a la Congregación para el clero por el Sumo Pontifice el 30 de enero de 2010 (17 de marzo de 2010). Comentario, Revista Española de Derecho Canónico 67/169 (2010) 931-933.

-, Los «graviora delicta» reservados a la Congregación para la Doctrina de la Fe. Texto modificado (2010), Revista Española de Derecho Canónico 68/170 (2011) 283-313.

Bernal Pascual, J., Nuevos desarrollos del procedimiento administrativo para la imposición de las penas, en La cooperación canónica de la verdad. Actas de las XXXII Fornadas de Actualidad Canónica (11-13 de abril de 2012), Dykinson, Madrid 2014, 131-162.

Bueno Salinas, S., Tratado general de Derecho Canónico, Atelier, Barcelona 2004, 476 pp.

CiTO, D., La pérdida del estado clerical ex officio ante las actuales urgencias pastorales, Ius Canonicum 51 (2011) 69-101.

Comentario exegético al Código de Derecho Canónico, Eunsa, Pamplona 1996, 6 volúmenes.

Cortés DiÉguez, M., Las fuentes del derecho canónico, en M. Cortés DiÉGUEZ - J. San José (coordinadores), Derecho Canónico, vol. I: El Derecho del Pueblo de Dios, BAC, Madrid 2006, 77-153.

—, La investigación previa y el proceso administrativo penal, Revista Española de Derecho Canónico 70/175 (2013) 513-545.

Filoni, F., La recepción del Código en los territorios de misión y las Facultades Especiales concedidas a la Congregación para la Evangelización de los Pueblos, Universidad San Dámaso, Madrid 2015, 23 pp.

Fuentes, J. A., Nuevo Reglamento de la Congregación para la Doctrina de la Fe sobre el examen de las doctrinas, Ius Canonicum 38 (1998) 301-341. 
García Matamoro, L. A., El proceso judicial penal cc. 1721-1728 CIC 83, Revista Española de Derecho Canónico 70/175 (2013) 547-564.

-, Secretaría de Estado, «rescriptum ex audientia SS.MI» sulla istituzione di un collegio, all'interno della Congregazione per la Dottrina della Fede, per l'esame dei ricorsi di ecclesiastici per i delicta graviora, Revista Española de Derecho Canónico 72/178 (2015) 319-323.

Golab, M., Facultades especiales para la dimisión del estado clerical (Congregación para el Clero de 30 de enero de 2009). Análisis y comentario, Ius Canonicum 50 (2010) 671-683.

Granado Hijelmo, I., Tratamiento penal del abuso de menores en el Derecho canónico general y particular de los Estados Unidos de América, Fidelium Iura 15 (2005) 135-176.

HerranZ, J., Salus animarum, «principio dell'ordinamento canonico», Ius ecclesiae 12/2 (2000) 291-306.

LabandeIra, E., Tratado de derecho administrativo canónico, Eunsa, Pamplona 1993, 536 pp.

Miras, J. - Canosa, J. - Baura, E., Compendio de derecho administrativo canónico, Eunsa, Pamplona 2001, 355 pp.

PÉREZ-MADRID, F., Derecho administrativo sancionador en el ordenamiento canónico: una propuesta para su construcción, Eunsa, Pamplona 1994, 266 pp.

VIANA, A., El gobierno de la diócesis según el Derecho en el directorio «Apostolorum Successores», Ius Canonicum 46 (2006) 639-659. 